RU Использование креолизованных текстов для повышения уровня лингвистической вежливости высказывания в виртуальной коммуникативной среде

Баев Е. В.

Аннотация. Цель исследования - описать связь иконического и вербального элементов в креолизованных текстах в свете теории лингвистической вежливости. Научная новизна исследования определяется недостаточной изученностью рассматриваемого языкового материала (креолизованные тексты, использующиеся в виртуальной коммуникации) и позицией его анализа (креолизованные тексты впервые рассматриваются в качестве ликоугрожающих актов). Также в тексте статьи впервые исследованы роль и специфика прагматического воздействия иконического элемента креолизованных текстов в качестве элемента ликоугрожающего акта. В результате проанализированы креолизованные тексты, сочетающие иконические и вербальные элементы, использовавшиеся в коммуникации в мессенджере Telegram и на других коммуникативных площадках в виртуальной среде; описаны принципы использования и прагматическая роль языковой игры в данных текстах; выдвинуты предположения касательно роли иконического элемента в ликоугрожающих актах.

\title{
EN Creolized Texts as Means to Increase Linguistic Politeness Degree in Virtual Communicative Space
}

\author{
Baev E. V.
}

\begin{abstract}
Relying on the linguistic politeness theory, the author reveals interrelation of iconic and verbal elements in creolized texts. Scientific originality of the study is conditioned by the fact that creolized texts in virtual communication are still poorly investigated and also by the fact that creolized texts are for the first time considered as face-threatening speech acts. Moreover, iconic elements of creolized texts are for the first time considered as elements of face-threatening speech acts. The research findings are as follows: the author analyses creolized texts containing iconic and verbal elements and functioning in virtual communicative spaces such as Telegram Messenger; describes pragmatic functions of language game in these texts; proposes a hypothesis on the role of iconic elements in face-threatening speech acts.
\end{abstract}

\section{Введение}

Актуальность настоящего исследования обусловлена растущим интересом к изучению прагматических целей языковой игры в коммуникации, в том числе к увеличению или снижению вежливости высказывания с помощью языковой игры, а также высокой степенью актуальности рассматриваемого языкового материала, который сам по себе является слабоизученным пластом лингвистического материала, относящегося к интернет-коммуникации.

Следует отметить, что рассматриваемый материал - креолизованные тексты - неоднократно становился объектом изучения исследователей (см. Е. Е. Анисимова [1], Н. С. Валгина [2], О. Л. Каменская [8], О. В. Пойманова [11], Ю. А. Сорокин и Е. Ф. Тарасов [14]). Эти исследования в основном посвящены изучению структуры, принципов классификации и принципов конструирования смыслов таких текстов. Принцип же функционирования креолизованных текстов в качестве речевых актов, претендующих на часть живого общения, исследован недостаточно.

Изучение лингвистической (не)вежливости как отдельная сфера научных исследований активно привлекает внимание последние два десятилетия после программной статьи Дж. Калперера [10, с. 134]. При этом актуальность исследования текстов, функционирующих в качестве ликоугрожающих речевых актов в виртуальной среде (в том числе креолизованных), еще более возрастает в течение последних лет. Изучаются формы 
речевой агрессии, сформировавшиеся в среде Интернет (Т. А. Воронцова, 2016; Л. Р. Абдуллина, Е. В. Артамонова, 2017); ее этические и лингво-правовые характеристики (А. В. Курьянович, 2018); прагматическая и лингво-культурологическая значимость креолизованных текстов в качестве формы речевой агрессии в виртуальной среде (Н. И. Часовской, 2013) и пр. Обычно интерес авторов сосредоточен на негативных и разрушительных аспектах агрессии и невежливости, но есть и другие примеры: так, существует описание стратегий и тактик неаутентичной речевой агрессии (т.е. использующейся для построения солидарности между коммуникантами) в виртуальной среде (Т. Ш. Габдрафикова, 2018), однако данное описание сделано на иноязычном материале и не описывает специфики иконических элементов.

Для достижения указанной цели требуется реализация следующих задач: очертить границы предмета исследования и, как следствие, изучаемого языкового материала, опираясь на критерий их использования в прямой (директной) коммуникации; описать тенденции конструирования смысла в искомых креолизованных текстах; реконструировать (опираясь на смысл самих креолизованных текстов) цель их использования.

В качестве методов исследования мы используем анализ, синтез и лингвистическое наблюдение [15, с. 18] и опираемся на русский языковой материал, собранный с 2019 г. по 2020 г., полученный из стикеров мессенджера Telegram, входящих в качестве языковых знаков в наборы (стикерпаки), содержащие в себе вербальный элемент и имеющие 10000 скачиваний и более на момент декабря 2020 года, а также инварианты данных креолизованных текстов из среды Интернета.

Теоретической базой исследования являются труды Е. Е. Анисимовой, О. В. Поймановой, Ю. В. Щуриной по креолизованным текстам, Т. А. Гридиной, Е. А. Земской и Д. Крисла - по языковой игре, работы М. В. Захаровой, описывающие прагматический аспект языковой игры, и классическая теория вежливости, разработанная П. Браун и С. Левинсоном.

Практическая значимость работы состоит в возможности использования выводов для дальнейшей классификации креолизованных текстов с позиции их прагматической цели. Исследование имеет широкие перспективы в изучении специфики креолизованных текстов. Полученные выводы могут быть использованы в коммуникативной лингвистике, прагматике, исследованиях лингвистической вежливости, теории текста, а материалы - в вузах гуманитарного направления в спецкурсах, посвященных теории вежливости и ее интерпретациям, а также при изучении дисциплин, связанных с языковой игрой и вежливостью в прагматике.

\section{Креолизованные тексты в структуре коммуникации}

Креолизованными называются такие тексты, в структуре которых можно выделить две негомогенные части: вербальную (языковую/речевую) и невербальную (принадлежащую к другим знаковым системам, нежели естественный язык) [14, с. 180]. Согласно Е. Е. Анисимовой, доминантой поля паралингвистических средств в письменных текстах креолизованного типа являются иконические (изобразительные) средства [1, с. 8]. Роль таких текстов постоянно возрастает в условиях развития различных платформ интернет-коммуникации в связи с тем, что появляется возможность быстрой и двусторонней коммуникации, использующей и вербальные, и креолизованные тексты. Многие креолизованные и пиктографические тексты даже встроены в знаковую систему для общения на большинстве таких платформ.

Классификации креолизованных текстов основываются на наличии и соотношении структурных элементов, см., например, классификацию Е. Е. Анисимовой креолизованных текстов по наличию подписи и основного смыслосодержащего текста и их соотношению [Там же, с. 65-67] или классификацию О. В. Поймановой по «соотношению объема информации, переданной различными знаками, и по роли изображения» [11, с. 24].

Попытки классификации креолизованных текстов в среде Интернет в целом следуют той же парадигме. Они в основном опираются на особенности паралингвистической доминанты и на особенности модели конструирования новой единицы креолизованного текста [9; 16]. Исследователи отмечают, что креолизованные тексты создаются по шаблонам и имеют одинаковые структурные элементы [9]. Также акцентируется внимание на том, что «создание и тиражирование множественных креолизованных текстов... характерно для интернет-пространства, поощряющего любого желающего к развитию, переосмыслению и необходимой на его взгляд коррекции любого появившегося в сети креатива», причем при продуцировании новых единиц креолизованного текста намеренно используются элементы старых (картинка/текст или их части) [7, с. 41].

Ключом к вопросу о правомерности рассмотрения креолизованных текстов в качестве ликоугрожающих речевых актов является вопрос их классификации (и в нашем случае - креолизованных текстов, функционирующих в среде Интернет, особенно).

Нам представляется, что классификацию креолизованных письменных текстов в интернет-среде следовало бы начать с разделения их на тексты самостоятельные и служебные. Креолизованные тексты первой группы ситуативны, связны и уникальны. Они функционируют подобно плакату/афише/вывеске: какими бы ни были отношения между структурными элементами самого креолизованного текста, его автор не вступает в прямую коммуникацию с возможностью обратной связи.

Служебные тексты представляют собой единицы креолизованных текстов, обладающие большей степенью возможной повторяемости (т.к., по сути, являются частью более комплексной знаковой системы, использующейся регулярно) и выражают более простые смыслы.

Для сравнения: интернет-комикс [9], выражающий сравнительно сложную мысль, является цельным текстом, обладающим высокой степенью связности. Он обладает только той коннотацией, которая заложена 
в основную его мысль и воспроизводится в основном в ситуации, когда данная мысль является новой для собеседника (по мнению того коммуниканта, который воспроизводит данный текст). Стикер в мессенджере, выражающий более простую мысль (например, заменяя слова благодарности, приветствия, брань и пр.), может воспроизводиться часто, становясь еще одной единицей комплексной знаковой системы, принятой между коммуникантами.

Именно такие тексты (креолизованные, использующиеся в непосредственной коммуникации между двумя и более коммуникантами, служащие для выражения простых мыслей) и находятся в поле нашего рассмотрения.

Может ли такой креолизованный текст являться т.н. «креолизованным речевым актом»? Дж. Серль пишет: «Вопреки распространенному мнению единицей языкового общения является не символ, не слово, не предложение и даже не конкретный экземпляр символа... а производство этого конкретного экземпляра в ходе совершения речевого акта» [12, с. 152], тем самым отвергая формальные ограничения на то, что должно считать единицей речи. А. Вежбицка пишет: «Универсум речи не образуется ни словами, ни предложениями: он образуется высказываниями (речевыми актами)» [3, с. 99]. Предметом теории речевых актов «являются единицы, гораздо теснее связанные с действительностью, чем те, которыми занималось языкознание прошлого» (фонемы, морфемы, слова, фразы) [Там же]. В связи с этим исключать иконический элемент креолизованного текста в коммуникации, демонстрирующей явные признаки двусторонности и действия коммуникантов с учетом коммуникативных лиц друг друга (например, при письменном общении в Интернете), мы считаем некорректным.

Могут ли креолизованные речевые акты находиться в позиции ликоугрожающих актов? Понятие ликоугрожающего акта введено П. Браун и С. Левинсоном в их теории вежливости. Ликоугрожающий речевой акт это такой речевой акт, который угрожает социальному лицу коммуниканта. Социальное лицо же понимается как конструкт, описывающий две стороны прагмалингвистического поведения говорящего и слушающего: стремление к сохранению свободы действий («защита территории») и стремление понравиться другим [18, р. 62]. Угроза каждого речевого акта зависит от социальной дистанции, власти одного из субъектов коммуникации над другим и степени накладываемых обязательств. Учитывая, что привнесение иконического элемента не снимает озвученные прагматические мотивации коммуникантов, мы снова не находим причин исключать креолизованный текст в основе речевого акта из потенциально несущих угрозу коммуникативным лицам говорящего и слушающего.

\section{Прагматический аспект использования креолизованных текстов в прямой коммуникации}

Прагматический смысл использования именно креолизованных текстов в качестве основы для речевого акта может крыться в самой природе таких текстов.

По мнению Л. В. Головиной, «наложение концепта вербального текста на концепт изображения приводит к созданию единого общего концепта (смысла) креолизованного текста». Она указывает, что комбинация вербального текста и изображения (особенно находящихся в отношениях синонимии или дополнения) приводит к тому, что читатель воспринимает данный текст более опосредованно, за счет чего крайне сужаются возможное поле интерпретаций данного сообщения и его эмоциональность [4, с. 9].

В частности, Е. Е. Анисимова, со ссылкой на Ю. Н. Тынянова и Г. Прессера, пишет о том, что и литературоведы, и специалисты по художественному оформлению книг предостерегают от излишнего использования иконических средств, так как изображение способно сковать воображение читателя [1, с. 13-14]. Это, в частности, объясняется эстетической функцией художественной речи. По мнению Г. Я. Солганика, слово в художественном произведении «двоится»: оно имеет то же значение, что и в общем литературном языке, а также добавочное, приращённое, связанное с художественным миром, содержанием данного произведения, и именно поэтому в художественной речи слова приобретают особенную глубину и значат больше, нежели в обычной речи [13, с. 196-197].

Однако то, что является возможным недостатком при использовании креолизованного текста в художественном тексте, в рамках разговорной письменной речи может стать преимуществом. За счет снижения потенциальной информативности достигается либо однозначность передаваемого сообщения, либо хотя бы сужение русла его возможной интерпретации. За счет этого уменьшается и угроза социальному лицу коммуниканта.

Таким образом, иконический элемент креолизованного текста может использоваться для задания безопасного направления интерпретации используемого вербального элемента. На данный момент мы находим два основных языковых факта в пользу этого утверждения.

Во-первых, такие креолизованные тексты часто включают в себя языковую игру. Ранее мы провели лингвистическое интервьюирование, в рамках которого носителям языка предлагалось несколько вариантов схожих речевых актов, различающихся на локутивном уровне, но употребляющихся в типичных контекстах и частично совпадающих на иллокутивном/перлокутивном уровнях. В качестве материала использовались лексемы («спасибо», «пожалуйста») и высказывания («вы парковаться вообще умеете?» и пр.), противопоставленные их инвариантам, образованным с помощью языковой игры разных уровней («посебо/пасиб», «позязя, плез» и «паркуетесь по слуху?» и т.п.). Респондентам было предложено ответить, изменяется ли уровень вежливости высказывания при использовании языковой игры.

Мы отметили, что респонденты часто указывают на нарочитую неграмотность таких языковых средств, как «пасиба», «спосебо», «плез», «позязя», в качестве аргумента, указывающего на невежливость данных высказываний или, по крайней мере, их сниженную вежливость по сравнению со словами, являющимися основой 
для этой фонетической языковой игры («спасибо»/«пожалуйста»). Кроме того, ошибки при интерпретации данных лексем приводили к тому, что коммуниканты делали далеко идущие выводы о причине использования подобных языковых средств, не имеющие ничего общего с причинами, обычно перечисляемыми исследователями в качестве причин, почему люди используют языковую игру. Так, респонденты указывали на ощущение, что лексемы сигнализируют о равнодушии коммуниканта, оставляли впечатление, что у него «нет времени нормально поблагодарить/попросить», что он «не оценил помощи» и т.п.

Однако на примере «стикеров» для коммуникативной платформы Telegram мы видим, что данное нарушение языковых норм является преднамеренным - стикеры являются предсозданными текстами, распространяемыми между участниками общения и используемыми повсеместно, объединенными тематически. Преднамеренное нарушение языковой нормы с расчетом на опознание реципиентом негласных правил игрового кода общения Т. А. Гридина связывает с механизмами языковой игры [5, с. 26]. Т. А. Гридина и С. С. Талашманов пишут, что намеренное использование неправильного написания используется для подчеркивания иронии высказывания [6, с. 33]. Подобная языковая игра является регулярной частью знаковой системы, принятой в общении многих коммуникантов.

Вербальные элементы рассматриваемых креолизованных текстов включают в себя примеры следующих вербальных текстов, воспроизводимых с той или иной степенью точности (но почти всегда сохраняющих языковую игру) в стикерпаках Telegram и креолизованных текстах, которыми обмениваются пользователи в социальных сетях: «спосеба», «спосеба кобан», «а када кушоть?», «нет слов, адни эмоцыи», «штош», «я сейчас злюся», «стлесс» и пр. Также регулярно появляется языковая игра на синтаксическом уровне для создания того же эффекта: «опять эти ваши утры», «можно не надо», «я тебе какое плохое зло сделал?» и пр. Для создания креолизованных текстов часто используются фотографии котов, попугаев и иных животных, как бы объясняющих появление лексических и синтаксических ошибок, указывающих на их преднамеренность и игровую природу. Иконический элемент используется в качестве ассоциативного характеризующего элемента, задающего тональность и русло интерпретации вербального.

Во-вторых, вербальные элементы подобных креолизованных текстов могут и время от времени включают в себя вербальный текст с речевыми актами, в иных обстоятельствах ставшими бы ликоугрожающими, чья неверная интерпретация рисковала бы нарушить ход коммуникации. В изучаемой же форме они представляют собой вид эксплицитно выраженной речевой агрессии, которая при этом не оскорбляет коммуниканта, который описан в зарубежной лингвистике посредством термина “non-genuine impoliteness” («неискренняя/неистинная невежливость») [17, р. 788], через которую реализуются дружеские межличностные отношения, известные как “friendly banter” («дружеское подтрунивание»).

Можно даже сказать, что такая невежливость (с использованием языковой игры и без) является одним из наиболее популярных инструментов для создания креолизованных текстов с целью использования в прямой коммуникации: «тебя что-то не устраивает?» (с изображением кота, вставшего на ногу человеку); «о нет, опять ты» (с изображением кота у двери); «печень вырву» (маленький котенок с нарочито насупленной мордой); «теперь хорошо видно, насколько мне плевать?» (кот, смотрящий в камеру через зеркало), «какой-то ты сегодня вежливый. Если от меня чего-то надо, то сразу говорю: иди к черту» и пр. Иконический элемент в данном контексте уже не столько объясняет смысл использования именно таких языковых средств или языковой игры, сколько оправдывает их использование, снижая степень угрозы речевого акта самим фактом того, что он сопровождается картинкой.

\section{Заключение}

На основании вышеизложенного можно сделать следующие выводы. Во-первых, креолизованные тексты в интернет-коммуникации используются в письменной разговорной речи, становясь частью принятой знаковой системы. Эти креолизованные тексты могут включать или не включать в себя языковую игру. По сравнению с большинством уже рассматривавшихся исследователями жанров креолизованных текстов, создающихся и распространяющихся в интернет-среде (демотиваторы, «аткрытки» и пр.), они несут в себе более простое, короткое сообщение, и их можно использовать неограниченное количество раз - тем самым данные тексты уподобляются знакам.

Во-вторых, иконические средства в таких креолизованных текстах служат двум целям: в качестве характеризующего иконического средства, задающего тон и русло интерпретации и объясняющего выбор тех или иных языковых средств и/или языковой игры; а также в качестве оправдывающего иконического средства, не столько объясняющего выбор языковых средств, сколько указывающего на необходимость его «несерьезной» интерпретации.

В-третьих, сочетание орфографической/фонетической языковой игры, выраженной в неправильном написании слов и/или нарушении синтаксических норм, и иконического элемента (с частотно используемыми изображениями животных) не является случайным. Данное сочетание представляет собой естественным образом сформировавшийся особый тип речевого акта, где каждый элемент служит конечной цели: языковая игра уменьшает степень угрозы речевого акта, позволяя употреблять инвективную лексику и/или конструкции с семантикой, обычно обладающей высокой степенью риска, а иконический элемент задает тон и русло интерпретации (как правило, подчеркивая иронию и несерьезность высказывания). 
Перспективы дальнейшего изучения мы видим в исследовании условий использования креолизованных текстов в живой коммуникации. Несмотря на очевидный договорной характер использования таких знаковых элементов, вероятно наличие стилевых, гендерных и прочих ограничений, препятствующих или, наоборот, поощряющих использование креолизованных текстов для снижения/увеличения уровня угрозы социальным лицам коммуниканта. Также представляет интерес вопрос, для какой цели креолизованные тексты используются чаще: для снижения или все же для увеличения угрозы социальным лицам собеседника.

\section{Список источников}

1. Анисимова Е. Е. Лингвистика текста и межкультурная коммуникация (на материале креолизованных текстов): учебное пособие для студентов факультетов иностранных языков. М.: Академия, 2003. 128 с.

2. Валгина Н. С. Теория текста. М.: Логос, 2003. 173 с.

3. Вежбицка А. Речевые жанры // Жанры речи: сб. науч. ст. / под ред. В. Е. Гольдина. Саратов: Колледж, 1997. C. 99-111.

4. Головина Л. В. Влияние иконических и вербальных знаков при смысловом восприятии текста: автореф. дисс. ... к. филол. н. М., 1986. 21 с.

5. Гридина Т. А. Языковая игра: стереотип и творчество: моногр. / Урал. гос. пед. ун-т. Екатеринбург, 1996. 215 с.

6. Гридина Т. А., Талашманов С. С. Языковая игра в современной интернет-коммуникации: метаязыковой аспект // Политическая лингвистика. 2019. № 3 (75). С. 31-37.

7. Захарова М. В. Иронические регулятивы в профессиональной коммуникации // Организационная психолингвистика. 2018. № 4 (4). С. 29-47.

8. Каменская О. Л. Лингвистика на пороге XXI века // Лингвистические маргиналии / отв. ред. Т. А. Амирова. М.: МГЛУ, 1996. С. 13-21.

9. Левченко М. Н., Изгаршева А. В. Креолизованный текст в системе «Интернет» [Электронный ресурс]. URL: https://cyberleninka.ru/article/n/kreolizovannyy-tekst-v-sisteme-internet (дата обращения: 16.11.2020).

10. Леонтьев В. В. «Темная сторона» вежливости: историко-прагматический анализ номинаций ее субъектов в русской лингвокультуре [Электронный ресурс] // Мир лингвистики и коммуникации: электронный научный журнал. 2018. № 4. С. 132-162. URL: https://www.researchgate.net/publication/331072476_Leontev_VV_ Temnaa_storona_vezlivosti_istoriko-pragmaticeskij_analiz_nominacij_ee_subektov_v_russkoj_lingvokulture_2018_ Victor_Leontyev_The_dark_side_of_politeness_historic-pragmatic_analysis_of_nomina (дата обращения: 23.02.2021).

11. Пойманова О. В. Семантическое пространство видеовербального текста. М.: Академия, 1997. 237 с.

12. Серль Дж. Р. Что такое речевой акт? // Новое в зарубежной лингвистике. 1986. Вып. 17. С. 151-169.

13. Солганик Г. Я. Стилистика текста: учеб. пособие для студентов, преподавателей-филологов, аспирантов. М.: Флинта; Наука, 1997. 253 с.

14. Сорокин Ю. А., Тарасов Е. Ф. Креолизованные тексты и их коммуникативная функция // Оптимизация речевого воздействия / отв. ред. Р. Г. Котов. М.: Наука, 1990. С. 180-186.

15. Стернин И. А., Рудакова А. В. Психолингвистическое значение слова и его описание. Saarbrücken: Ламберт, 2011. 192 с.

16. Шурина Ю. В. Комические креолизованные тексты в интернет-коммуникации // Вестник Новгородского государственного университета им. Ярослава Мудрого. 2010. № 57. С. 82-86.

17. Bernal M. Do Insults Always Insult? Genuine Impoliteness versus Non-genuine Impoliteness in Colloquial Spanish // Pragmatics. Amsterdam: John Benjamins Publishing Company, 2008. P. 775-802.

18. Brown P., Levinson S. Politeness: Some universals in language usage. Cambridge: Cambridge University Press, 1987. $345 \mathrm{p}$.

\section{Информация об авторах | Author information}

\section{RU Баев Евгений Владимирович ${ }^{1}$}

${ }^{1}$ Московский городской педагогический университет

EN Baev Evgeniy Vladimirovich ${ }^{1}$

${ }^{1}$ Moscow City Pedagogical University

${ }^{1}$ baevev@mgpu.ru

\section{Информация о статье | About this article}

Дата поступления рукописи (received): 23.01.2021; опубликовано (published): 09.04.2021.

Ключевые слова (keywords): языковая игра; креолизованный текст; лингвистическая вежливость; ликоугрожащие акты; коммуникация в виртуальной среде; language game; creolized text; linguistic politeness; facethreatening speech acts; virtual communication. 